\title{
Clinico-epidemiological and Socio-economic Profile of Cataract Patients from Rural Areas of Eastern Rajasthan
}

\author{
Mahaur V. ${ }^{1}$, Devendra J. ${ }^{2}$ \\ ${ }^{1}$ Dr. Vandana Mahaur, Assistant Professor, ${ }^{2}$ Dr. Jaya Devendra, Professor; both authors are affiliated with Department of \\ Ophthalmology at National University of Medical Sciences, Jaipur. \\ Corresponding Author: Dr. Vandana Mahaur, Assistant Professor, Department of Ophthalmology, National Institute of \\ Medical Sciences, Jaipur, India. E-mail: vandanarai10@gmail.com
}

\begin{abstract}
Introduction: Blindness due to cataract is a global health problem. In India also it is the major cause of blindness in $62.4 \%$. The prevalence of cataract is more in rural population owing to lack of infrastructure and manpower as well as illiteracy and poverty. There is a paucity of data on the subject from rural Rajasthan especially the eastern region. In order to optimize limited health care facilities for the target population, it is necessary to know the clinicoepidemiological and socio-economic factors associated cataract; thus, the study was conceptualized. Materials and Methods: This cross-sectional study was conducted in the National Institute of Medical Sciences, a tertiary care center situated in the rural area of Jaipur from January 2018 to December 2019. Patients having cataract and giving consent to participate in the study were included. Results: Eight hundred and eleven cataract patients were included in the study. The majority (53.3\%) of cataract patients were aged and males (55.9\%). Most patients were illiterate (68.5\%) and belonged to low socio-economic status $(88.7 \%)$. Diabetes and hypertension were common. In our setting, senility was the most frequent cause $(91.1 \%)$ followed by trauma (5.3\%); Congenital cataract was least common (1.7\%). Sixty-four percent of total cataract patients had bilateral affection. Majority of patients (45\%) had immature cataract, $39.9 \%$ had mature and 15\% had hyper-mature cataract. Conclusion: Socioeconomic and clinico-epidemiological profile of patients living in the rural population of eastern Rajasthan share similarities with people living in other rural areas of our country.
\end{abstract}

Keywords: Blindness, Cataract, Rural, India.

\section{Introduction}

As per the World Health Organization (WHO), the estimated number of visually impaired population in the world is 285 million. There are 39 million blind people and as high as 246 million people who are having low vision. Sixty-five percent of people who are visually impaired and $80 \%$ of all blind people all are above 50 years of age. Cataract is the leading cause of blindness worldwide which is related to aging in most of the cases. Cataract account for more than half of all causes of blindness [1].

The proportion of vision impairment attributable to cataract is higher in low- and middle-income countries than high-income countries. In high-income countries, diseases such as diabetic retinopathy, glaucoma, and age-related macular degeneration are more common. To estimate the incidence of blindness in India, the first

Manuscript received: $14^{\text {th }}$ May 2019

Reviewed: $24^{\text {th }}$ May 2019

Author Corrected: $30^{\text {th }}$ May 2019

Accepted for Publication: $3^{\text {rd }}$ June 2019 survey by the central government was conducted in the year 1971-1974. The survey showed that $1.4 \%$ of the Indian population is blind, and in total 12 million blind people live in India. The National Program for the control of Blindness was started in 1976; later the name of this organization was changed to National Program for the Visual impairment and Blind (NPCB) [2]. A scientific study was conducted in the year 1999-2001 to assess the work undertaken by the NPCB.

The study showed that the incidence of treatable blindness was reduced from $1.4 \%$ to $1.1 \%$. Cataract emerged as the major cause of blindness in $62.4 \%$ followed by refractive errors $(19.65 \%)$, glaucoma $(5.83 \%)$, corneal blindness $(0.89 \%)$, and posterior segment diseases $(4.72 \%)$. This survey was conducted on people above 50 years of age; cataract was the cause of bilateral blindness in $50 \%-80 \%$ of patients [3]. Cataract as a cause of blindness is not only limited to rural areas of India but also becoming more common in 


\section{Original Research Article}

urban Population [4]. Rajasthan state of India has the second highest prevalence of blindness in the country after Tamilnadu. As per the national census of India in 2011, 2.5\% people out of 68.6 million people of Rajasthan are affected by blindness [5].

In India, due to lack of infrastructure and trained personals, the government alone cannot meet the health demands of all. To add, number of other hindrances like poverty, illiteracy and the growing number of elderly populations also lead to inaccessibility of available resources.

A lot of private organizations and international nongovernmental organizations (NGO) are fighting against blindness due to cataract by supporting free camps. The things are better, but there is still a long way to go to achieve the WHO goal of eliminating blindness by the year 2020, which is unfortunate as most blindness which is due to cataract is curable.

To eradicate blindness, it is important to know its stature especially in a rural population where health resources are largely scarce and inaccessible. In order to mobilize the resources and effectively manage blindness especially cataract, it is important to have the knowledge of clinico-epidemiological and socioeconomic factors associated with the disease. There is a paucity of data on the subject from the rural area of eastern Rajasthan. Such information will be helpful for optimizing limited health care facilities.

Therefore, the present study was conducted in cataract patients visiting the Ophthalmology department of a tertiary health care center situated in a rural area of eastern Rajasthan to study the clinico-epidemiological and socio-demographic profile of cataract patients.

\section{Materials and Methods}

This was a unicenteric, hospital based, cross sectional and non-interventional observational study conducted in department of Ophthalmology, National Institute of Medical Sciences, Jaipur from January 2018 to December 2018. All consecutive patients who visited the outpatient department of Ophthalmology, National Institute of Medical Sciences, Jaipur during the study period were screened for the presence of Cataract. A detailed history was taken using a structured questionnaire. Socioeconomic status was categorized according to the modified Kuppuswamy classification [6]. Diagnosis of cataract was made on the basis of detailed ophthalmic examination. Cataract was further classified as immature, mature and hypermature clinically.

Inclusion criteria: Patients of either sex diagnosed to have unilateral or bilateral cataract on ophthalmic examination; and giving consent to participate in the study were included.

Exclusion Criteria: Those patients who did not give consent were excluded from the study.

Ethical consideration: Ethical Guidelines laid down by ICMR (2006) and Helsinki declarations (2013) were followed in conducting the study. There were no ethical issues as identity or socio-economic status of the participants was not disclosed.Ophthalmic consultations and tests were conducted free of cost; and details of surgery/outcomes were not studied.

Data collection and analysis: Data were recorded in a detailed proforma. The categorical data were then tabulated and expressed as numbers and percentages.

\section{Results}

In this cross-sectional study, the data were analysed from 811 patients who visited our center having unilateral or bilateral cataract, and willing to be included in the study. Majority of patients $(53.3 \%)$ of cataract were old (more than 64 years of age). Younger cataract patients $(<15$ years of age) were only few in numbers $(1 \%)$.

Males outnumbered females; 454 (55.9\%) were males and 357 (44.1\%) were females.

The present study showed that in our setting, senility was the most frequent cause $(91.1 \%)$ of cataract followed by trauma (5.3\%). Congenital cataract was the least common variety of cataract and was seen in only $1.7 \%$ of patients [Table 2]. It was seen only in children and young adults ( $<25$ years of age). Our study demonstrated that $64 \%$ of total cataract patients had bilateral cataract. Majority of patients (45\%) had immature cataract, 39.9\% had mature and 15\% had hyper-mature cataract [Table 3]. Diabetes and hypertension were also seen in $10.9 \%$ and $26 \%$ of patients of cataract respectively.

Most of the patients were illiterate (68.5\%). Only 1.2\% patients were graduates. Again, majority of patients were poor and belonged to low socio-economic status (88.7\%) [Table 1]. 
Table-1: Demographic and clinico-epidemiological profile of cataract patients.

\begin{tabular}{|c|c|c|}
\hline & No. of patients with cataract & Percentage of patients with cataract $(\%)$ \\
\hline \multicolumn{3}{|l|}{ Age group } \\
\hline$<15$ years & 8 & 1.0 \\
\hline $15-24$ years & 18 & 2.2 \\
\hline $25-44$ years & 41 & 5.0 \\
\hline 45-64 years & 312 & 38.5 \\
\hline$\geq 65$ years & 432 & 53.3 \\
\hline Total & 811 & 100 \\
\hline \multicolumn{3}{|l|}{ Sex } \\
\hline Male & 454 & 55.9 \\
\hline Female & 357 & 44.1 \\
\hline Total & 811 & 100 \\
\hline \multicolumn{3}{|l|}{ Socio-economic status } \\
\hline Upper & 9 & $1.1 \%$ \\
\hline Middle & 81 & $9.9 \%$ \\
\hline Lower & 721 & $88.9 \%$ \\
\hline Total & 811 & $100 \%$ \\
\hline \multicolumn{3}{|l|}{ Education } \\
\hline Illiterate & 556 & $68.5 \%$ \\
\hline Primary & 162 & $19.9 \%$ \\
\hline Secondary & 57 & $7.0 \%$ \\
\hline Higher secondary & 26 & $3.2 \%$ \\
\hline Graduate and above & 10 & $1.2 \%$ \\
\hline \multicolumn{3}{|l|}{ Comorbidity } \\
\hline Diabetes & 89 & $10.9 \%$ \\
\hline Hypertension & 211 & $26 \%$ \\
\hline
\end{tabular}

Table-2: Etiology of cataract

\begin{tabular}{|c|c|}
\hline Etiology & No. of patients (\%) \\
\hline Senile & $746(91.9)$ \\
\hline Traumatic & $43(5.3)$ \\
\hline Congenital & $14(1.7)$ \\
\hline Other & $8(0.9)$ \\
\hline Total & $\mathbf{8 1 1 ( 1 0 0 )}$ \\
\hline
\end{tabular}

Table-3: Classification of cataract according to maturity

\begin{tabular}{|c|c|}
\hline Stage & No. of patients (\%) \\
\hline Immature & $365(45)$ \\
\hline Mature & $324(39.9)$ \\
\hline Hyper mature & $122(15)$ \\
\hline Total & $\mathbf{8 1 1 ( 1 0 0 )}$ \\
\hline
\end{tabular}




\section{Discussion}

This study was conducted in National Institute of Medical Sciences, a tertiary care center in Jaipur, India which caters to the rural population of districts of eastern Rajasthan. The study was aimed to know the demographic profile, socioeconomic status and clinical profile of cataract patients living in the rural areas of eastern Rajasthan which is demographically and culturally a different area from rest of Rajasthan. This analysis can help in optimizing the health infrastructure and manpower, as well as formulating a health policy to cater to the needs of a larger population living in this part of Rajasthan suffering from blindness due to cataract.

We studied 811 patients visiting our center and diagnosed to have cataracts. Most of our patients of cataract were more than 64 years of age $(53.3 \%)$. This observation goes in accordance with other studies from the rural population of different parts of India. Avachat et al. conducted an epidemiological study in rural Maharashtra and observed that $67.5 \%$ of all cataract patients were more than 60 years of age (in contrast to $3.7 \%$ patients who were younger than 15 years) [7]. Two studies from rural population of southern India by Singh et al. and Nirmalan et al. demonstrated that increasing age is the risk factor for the development of cataract $[8,9]$.

In the present study, male cataract patients visiting our center outnumbered females. This is in contrast to the higher prevalence of cataract in females than male patients as shown in a population study from village population of north and south India (the India-study of age related eye disease) [10]. Logically more females should visit a health care facility for the purpose of cataract surgery, however we have observed that more male patients visit a hospital for surgical options. Avachat et al. in their study from Maharashtra also showed that males visiting hospital constituted $61.7 \%$ of cataract cases [7].

The possible explanation for this difference lies in the fact that females are less privileged in rural areas and have less access to health care facilities. Mahajan et al. also commented that cataract extraction is 1.6 times more common among males although women are more commonly affected [11]. However, a study from a southern affluent state of India demonstrated, that among cataract patients more than 40 years of age who were operated, females outnumbered males $(53.9 \%$ vs $46.1 \%$ respectively) [12].
We observed that senility was the most common cause of cataract $(91.9 \%)$, other causes being less common. More than half of our patients had bilateral cataract. In the study by Avachat et al. age-related cataract was seen in $53.8 \%$ of cases, followed by metabolic cause $(26.5 \%) ; 52.5 \%$ of their patients had bilateral cataract [7]. In our study, $45 \%$ of patients had immature cataract followed by mature (39.9\%) and hyper mature (15\%) variety. Shori et al. also observed that most commonly, cataract patients presented with immature (65\%) followed by immature variety $(26 \%)$ [13].

Diabetes is said to be an important risk factor for the development of cataract. Nirmalan et al. showed that diabetes and hypertension, both ailments were associated with cataract on bivariate analysis [9]. On the contrary, Singh et al. in their study had demonstrated that only diabetes, but not hypertension was associated with increased risk of cataract [8]. We also demonstrated that in cataract patients, diabetes and hypertension was common; most of them were unaware of their ailment. In the study by Manhas et al. diabetes was seen in $19.44 \%$ and hypertension was seen in $38.89 \%$ of cataract patients, a pattern similar to what we have observed [14].

It was seen in our study that most patients of cataract belonged to low socio-economic status. Our observation is like that of Singh et al. who showed that in the rural population of south India, cataract is significantly associated with low-income group patients [8]. Manhas et al. in their study have shown that about half of the cataract patients from rural population of northern India were farmers and labourers [14]. We also observed that cataract was mainly associated with poor educational status. Nirmalan et al. and Avachat et al. had similar findings in their studies [7,9]. The association between education and cataracts is unclear; possibly there is less awareness of treatment options and lower surgical coverage for people with less education. Major limitation of our study is lack of control population. Only some of the cataract patients had the means to visit our center and may not be the true representative of the rural population. A population-based study with a larger sample size with age-matched controls should be able to give the necessary information to fill the gaps in our current knowledge.

\section{Conclusion}

To conclude, the socioeconomic and clinicoepidemiological profile of patients living in the rural 
population of eastern Rajasthan, barring few differences, share similarities with people living in other rural areas of our country.

Authors contributions: V.M. conceived the idea for the study, wrote the protocol, performed analyses, interpreted data, prepared the manuscript was involved in care of patients. J.D. performed analyses, interpreted data and prepared the manuscript.

What this study adds to existing knowledge? To the best of our knowledge, this is the first study to show the clinico-epidemiological and socio-economic status of cataract patients from the rural region of eastern Rajasthan.

\section{Funding: Nil, Conflict of interest: Nil \\ Permission from IRB: Yes}

\section{References}

1. Global data on visual impairments 2010 [Internet]. Geneva: World Health Organization; 2012 [cited 2019 June 23].Availablefrom: https:/www.who.int/ blindness / GLOBALDATAFINALforweb.pdf.

2. Mohan M. National Survey on Blindness-India. NPCB-WHO Report. New Delhi: Ministry of Health and Family Welfare, Government of India; 1989.

3. Murthy GV, Gupta SK, Bachani D, Jose R, John N. Current estimates of blindness in India. $\mathrm{Br} \mathrm{J}$ Ophthalmol. 2005 Mar; 89(3):257-60. doi:10.1136/bjo. 2004. 056937.

4. Vijaya L, George R, Asokan R, Velumuri L, Ramesh SV. Prevalence and causes of low vision and blindness in an urban population: The Chennai Glaucoma Study. Indian J Ophthalmol. 2014 April; 62(4):477-81. doi: 10. 4103/0301-4738.111186.

5. India National Census. Census of India 2011 [Internet]. New Delhi: Indian National Census; 2011 [cited 2019, June 23]Available from: www.censusindia. gov.in/2011-Common/CensusData2011.html.

6. Sharma, R. Revised Kuppuswamy's socioeconomic status scale: explained and updated Indian Paediatr. 2017 Oct 15; 54(10): 867-70.
7. Avachat SS, Phalke V, Kambale S. Epidemiological correlates of cataract cases in tertiary health care center in rural area of Maharashtra. J Fam Med Primary Care. 2014 Jan-Mar; 3(1): 45-7. doi: 10. 4103/ 2249-4863. 130273

8. Singh S, Pardhan S, Kulothungan V, Swaminathan G, Ravichandran JS, Ganesan S, et al. The prevalence and risk factors for cataract in rural and urban India. Indian J Ophthalmol. 2019 April;67(4):477-83. doi: 10.4103/ ijo. IJO_1127_17.

9. Nirmalan PK, Robin AL, Katz J, Tielsch JM, Thulasiraj RD, Krishnadas R, et al. Risk factors for age related cataract in a rural population of southern India: The Aravind comprehensive eye study.Br J Ophthalmol. 2004Aug;88(8):989-94. doi:10.1136/bjo. 2003. 038380.

10. Vashist P, Talwar B, Gogoi M, Maraini G, Camparini G, Ravindran RD, et al. Prevalence of cataract in an older population in India: the India study of age-related eye disease.Ophthalmology. 2011 Feb; 118 (2-19): 272-8.e2. doi: 10.1.1016/j. ophtha. 2010. 05.20

11. Mahajan B, Gupta M, Ray R, Saha I. Textbook of Preventive and Social Medicine, 4th edition. New Delhi: Jaypee Medical Publishers; 2012.

12. Vijaya L, George R, Rashima A, Raju, P, Arvind H, Baskaran M, et al. Outcomes of cataract surgery in a rural and urban south Indian population. Indian $\mathrm{J}$ Ophthalmol.2010;58(3):223-8.doi:10.4103/0301-4738. 62648

13. Shori C, Shori R, Laxmiprasad G, Alli A. A study of clinical and ophthalmologic profile of patients undergoing cataract surgery. Int J Res Med Sci. 2017 May; 5 (5): 2229-32.doi:10.18203/2320-6012.ijrms 20171874

14. Manhas A, Manhas RS, Manhas GS, Gupta D. Clinical-ophthalmological profile of patients undergoing cataract surgery following their identification in screening eye camps. Int J Med Sci Public Health. 2019;8(1):38-41. Doi 10.5455/ijmsph. 2019. 1028707102018 .

How to cite this article?

Mahaur V, Devendra J. Clinico-epidemiological and Socio-economic Profile of Cataract Patients from Rural Areas of Eastern Rajasthan. Trop J Ophthalmol Otolaryngol.2019;4(2):114-118.doi:10.17511/jooo.2019.i02.08 